\title{
Trade and Volatility at the Core and Periphery of the Global Economy
}

\author{
Julia Gray \\ University of Pennsyluania \\ AND \\ Philip B.K. PotTer \\ University of Michigan
}

\begin{abstract}
Researchers typically assume that economic openness increases volatility. But the conventional empirical shorthand for economic openness (trade as a share of overall income) fails to account for crucial distinctions in the way that states trade. States that are deeply incorporated into the core of the international trading network have very different experiences than states at the periphery with fewer, more marginalized trading partners. This article demonstrates that a position at the core of the international trading system rather than the periphery actually diminishes volatility. Thus, a country's position in the world economy can, independently of its overall volume of trade, moderate the risks of exposure to international markets. To demonstrate how this distinction might impact political outcomes and future scholarship, we show that this reduction in volatility allows governments to minimize compensation to their domestic publics.
\end{abstract}

As the tide of globalization has risen, many have questioned whether openness to international markets has negative consequences. ${ }^{1}$ Global exposure may increase economic volatility and with it the vulnerability of individuals to global market fluctuations (Prasad, Rogoff, Wei, and Kose 2004). Others argue that global competition contributes to the erosion of social spending and the welfare state as countries "race to the bottom" to attract investment. ${ }^{2}$ These studies typically rely on a simple shorthand for economic openness: the sum of a country's imports and exports as a share of overall income. ${ }^{3}$ But the causal mechanisms underpinning the notion that openness might have negative consequences rest on more than the volume of traded goods. Rather, many of the perceived dangers of globalization relate to a country's exposure to risk and its relative position in the global trading system. At issue is not just how much a country trades, but with whom. In short, a country's relational position in the world economy colors its experience with globalization, and these relations are best mapped and understood in terms of trade networks rather than country-level statistics.

\footnotetext{
1 The authors would like to thank Matt Baum, David Bearce, Bill Bernhard, Andrew Kerner, Ed Mansfield, Emilie Hafner-Burton, and Nita Rudra. All errors are our own. Replication data and instructions are available from the authors upon request.

${ }^{2}$ See Oates (1972), Lee and Mckenzie (1989), and Andrews (1994). But see Basinger and Hallerberg (2004) for an opposing view.

${ }^{3}$ See, for example, Leamer (1988) and Dollar (1992). Birdsall and Hamoudi (2002) are more skeptical, noting that countries that export commodities will have particularly high trade/GDP ratios but may not be open in other respects.
}

This article demonstrates that the traditional measure of openness to trade misses a key dimension of how states trade. First, it excludes diversification: States with more trading partners are better insulated from ordinary economic volatility than those with only a few. However, diversification alone is not enough to protect against volatility, because it fails to account for the stability and significance of these trading partners. Trade ties with countries that are connected to many well-connected partners will contribute to relatively greater stability because these countries are themselves more insulated and diversified.

To illustrate, consider three countries: the first with one isolated trading partner, the second with three isolated trading partners, and the third with three trading partners that in turn each have three trade partners of their own. In the context of routine trade volatility, the third country is more insulated than the second state, which is more insulated than the first. When combined with preferential attachment between stable trading states, this results in a global trade network that self-organizes into a more stable core and a less stable periphery. ${ }^{4}$

\footnotetext{
${ }^{4}$ The recent financial crisis has shifted attention from economic volatility to major shocks. The lesson many have taken from this experience is that connectedness and a position at the core of the international economic system is not insulation but rather a liability. The idea here is that problems at the core of the system can spread to the connected while sparing those at the periphery. While seemingly contradictory, this is consistent with the argument that we make here. Robustness in the face of routine volatility and vulnerability to a major crisis at the core of the international system are in fact flip sides of the same coin. In general, "hub and spokes" networks (which the international trading system resembles in key regards) are robust to random disruption but susceptible to problems at the core.
} 
A relational approach to the implications of trade adheres closely to the realities of the international economic system, which is characterized by broad linkages within the community of nations rather than just bilateral ties. Consider the situation of many island nations, which typically import far more than they export, or export only a few goods, such as commodities, to a few countries. Such countries have relatively high trade as a share of GDP but are peripheral to the trade network. Unsurprisingly, such states are notably vulnerable to shocks and volatility. By contrast, a country with significant trade relations with several countries that are themselves active in the global trade network is more central and, under most circumstances, more insulated from volatility.

The remainder of the paper proceeds as follows. The next section briefly reviews the relevant literature on volatility and how states respond to it. The third section discusses the theoretical and empirical advantages of network analysis as a tool for interpreting aspects of globalization that are not captured by the standard trade-to-GDP ratio. The fourth section demonstrates that states that are tightly integrated into the core of the international economic system suffer less economic volatility in terms of abnormal swings in income, output, consumption, and investment. To illustrate the impact of this change, we then demonstrate a relationship between network position and government spending, which we attribute to reduced volatility leaving governments free to pursue the competitive benefits of trade in lieu of compensating domestic publics. The final section concludes.

\section{Openness, Volatility, and Vulnerability}

In classical Ricardian trade theory, openness to trade allows countries to specialize in goods in which they have comparative advantage, thereby increasing welfare for all participating countries. Empirically, crossnational studies show a strong and positive relationship between a country's level of trade and its economic growth, as well as between open markets and growth. ${ }^{2}$ However, at least in the classical model, economic growth through trade comes at a price. These models imply that the competitive pressure of free trade will crowd out the welfare function of the state because the movement of factors should, through factor price equalization, lead to competition that undermines government spending. This apparent tension between optimal economic growth and the welfare function of the state is one of the central flashpoints of the debate on globalization. ${ }^{6}$

Despite the intuitive appeal of the "race to the bottom" argument, empirical evidence indicates that gov-

\footnotetext{
${ }^{5}$ The literature is too expansive to summarize in its entirety. On the merits of open trade, see Krueger (1998); see Edwards (1993) and Alesina, Spoloare, and Wacziarg (2003) on trade and growth in developing countries. There is also, however, a non-trivial amount of work that finds no relationship between trade and growth. See Edwards (1998); Rodriguez and Rodrik (2000); Dollar and Kraay (2001).

${ }^{6}$ Dreher, Sturm, and Ursprung (2008) provide a good summary of the current state of theoretical and empirical advances on this topic. The banner studies include, among others, Hicks and Swank (1992); Garrett (1995, 1998); Garrett and Mitchell (1997); Quinn (1997); and Rudra (2002, 2004).
}

ernment spending, at least in the developed world, has actually increased with the rise of globalization and trade openness. This observation gives rise to the compensation hypothesis; that is, that governments seeking to maintain a hold-on power will redistribute some of the gains from trade toward greater welfare spending. A significant body of empirical research grapples with this apparent contradiction, hoping to gain purchase with disaggregated measures of spending and globalization (Dreher et al. 2008) or by introducing previously omitted variables, such as structural changes in a country's economy that might be driving the process (Iversen and Cusack 2000). Taking a somewhat different tack, Rodrik argues that the missing link in the research on globalization and government spending is the relationship between openness and increased volatility (Rodrik 1997, 1998). Shocks in the global economy can throw countries with open markets into temporary disequilibrium, forcing governments to spend more abundantly in order to cushion the blow to their populations. Bolstering this argument, Kim demonstrates empirically that openness alone has less impact on government spending than external risk ( $\mathrm{Kim} 2007$ ).

However, the majority of the empirical studies hinge on a fundamental simplification-and, we argue, a misspecification-of the nature of openness. Policymakers and scholars have widely assumed that openness works in a consistent way, and accordingly, these studies operationalize openness in trade as a share of GDP. But all types of openness are not equivalent. At a given ratio of trade to GDP, it seems intuitive that reliance on trade partners that are themselves deeply integrated into the trade system provides a stable foundation, insulating a country from economic shocks in any one country in particular. The point is that the commonly used measure of total trade/GDP identifies an attribute of an individual state, but the meaning of openness and the origins of volatility are equally contingent on relations with other states, and we need measures of openness that incorporate this relational aspect of the economic system.

If the advantages of stable, diversified partners are widely recognized by states, this will result in a pattern of preferential attachment that will give rise to an international trading network with a core/periphery structure. States with connections will find it relatively easy to forge ties with other well-connected states. Those with less enviable positions are less attractive partners and will therefore find this process more difficult. Thus, connections at the connected center tighten, while the links at the periphery remain diffuse.

The implication of this logic is an expectation about volatility that is based on a state's place in the international trading network rather than exclusively on its individual behavior. If a country trades heavily with partners that are themselves important in the international trading system, it will translate into a position at the core of the trade network. Frequent interactions with several strong economies can insulate a country from an economic shock originating in one particular state-which could be damaging if that country were chained to a relatively small number of peripheral 
trading partners. A country's position in the trade network, then, could be an important precondition for stability as countries integrate their economies internationally. If countries open up to the global economy with asymmetric relationships, relying too heavily on one trading partner or on several partners that are peripheral to the core of the system, they are left exposed to short-term fluctuations that may increase volatility. ${ }^{7}$

Take, for example, the postcommunist countries of Eastern Europe. After the collapse of the Soviet Union in 1991, many of these countries were faced with the choice of keeping their established trade ties with the former Soviet Union or directing trade toward the European Union. Even though the number of trading partners would have been higher in the East, most of the Central European countries chose to direct their trade toward Germany and France because, in addition to being richer countries, they were much more central to the European and global trading networks and correspondingly more stable. Here, fewer but better linked trading partners were more valuable than a multitude of peripheral ones.

\section{Thinking about Trade Relationally}

It is appropriate to consider trade openness in terms of networks in part because of the nature of the data itself. There are two sorts of data relevant to this discussion: attribute data and relational data. Attribute data describes the qualities of agents (states, in the present discussion)-GDP, population, and oil production, for example. Standard statistical techniques are designed to uncover relationships in such data. However, a great deal of data in political science, including most data with which we might operationalize aspects of globalization such as trade, is relational data-the contacts, ties, connections, and transfers between agents that cannot be cleanly reduced to properties of the agents themselves because they describe their interactions (Scott 1991).

Consider the trade data commonly used in measures of economic openness. When researchers assign imports to states, they are effectively taking a flow, thought of graphically as a line (or "edge") between two states (or "nodes") and artificially reducing it to an attribute of a state. Not only does this limit the analysis to counting only imports or exports and discarding the other in order to avoid redundancy, but it also obscures the fact that an import into one country is an export from another. It would be far better to consider a broader network of trade, which can map the flow of exchange through the entire international system. A state that is more central to a network of countries is embedded in a complex web of existing as well as potential relationships, different from the bilateral ties explored in most models of trade and economic growth (Lazer 2003).

\footnotetext{
${ }^{7}$ It is possible that diversification may not have this proposed positive effect for exporters of a single commodity that is priced in an international market; oil, for example. However, this situation would introduce conservative bias into the empirical analyses that follow.
}

Relational analysis has gained traction in many areas of international relations. ${ }^{8}$ Part of the reason that network theory has been influential is because it offers an array of developed and readily accessible tools with which to explore the broader structure of the relationships between actors. Measures of network centrality provide a simple way to characterize the relational importance of each state in a matrix of relationships and therefore serve as a useful empirical approximation of the relative integration of a state into the globalized international system. Centrality measures evaluate the location and prominence of actors or nodes in the network based on network position alone and can therefore be thought of as a structural attribute of the nodes in a network. Thus, centrality measures can add relational elements into a standard statistical model. It is therefore possible to retain some measure of comparability with existing findings while capturing the deeper interrelationships between the node and the broader network.

We use two measures of centrality to operationalize key independent variables: degree centrality to capture simple diversification and eigenvector centrality to identify whether a state is at the core or periphery of the international trading system. Degree centrality simply counts the number of trading connections that a node has in a network. In the context of the international trading system, this is the number of states with which a given state maintains significant trading relationships. ${ }^{9}$ More in-depth discussion of the eigenvector measure is warranted, as both the measure itself and the underlying phenomenon that we seek to characterize are more complex. ${ }^{10}$

Eigenvector centrality assesses the importance of a node by considering the importance of its neighbors. The measure is commonly used to characterize prestige and power, but it can also describe prominence in the trading system that we are attempting to identify. The central concept, developed by Alexander (1963) and further developed by others (Bonacich 1972), is that the relevant issue is not just how many partners a given state has, but also how many partners these states have in their own right. The extension of this logic to trade and volatility is relatively clear. A state with deep trade ties to the core of the network (high eigenvector centrality) is more likely to be insulated from volatility than one that is not-even if the second country has a relatively high number of first-degree trading partners.

This measure is described in equation 1 , which produces a system of equations (since the definition is

\footnotetext{
${ }^{8}$ See Marin and Mayntz (1992); Marsh and Rhodes (1992); Huckfeldt, Beck, Dalton, and Levine (1995); Mintrom and Vergari (1998); and Fowler (2006). For a much more complete discussion of the burgeoning use of networks in international relations, see Kahler (2009) and Hafner-Burton, Kahler, and Montgomery (2009). For applications, see Hafner-Burton and Montgomery (2006) and von Stein (2008).

${ }^{9}$ In the analysis that follows, we adhere to past practice and treat $4 \%$ of GDP of the joint GDP of the dyad as the threshold for significance (Kali and Reyes 2006). The findings are robust for thresholds ranging from $2 \%$ to $8 \%$ of GDP.

${ }^{10}$ There are other measures of centrality: for example, closeness and betweenness (Freeman 1979). This analysis focuses on degree and eigenvector centrality because we argue that they most immediately operationalize the objects of core theoretical interest.
} 
explicitly self-referential) from which we derive an adapted measure of eigenvector centrality for each state in the international system for each year in our period of analysis (1976-2001). The eigenvector centrality of a state derives from the sum of the eigenvector centralities of those states with which it has a firstdegree link:

$$
\lambda C_{i}^{e}(g)=\Sigma_{j} g_{i j} C_{j}^{e}(g)
$$

In matrix notation:

$$
\lambda C^{e}(g)=g C^{e}(g)
$$

where $\lambda$ is a proportionality factor. The result is that $C^{e}(g)$ is an eigenvector of $g$, and $\lambda$ is its eigenvalue (Jackson 2008).

This measure simultaneously accounts for the overall volume or magnitude of the international interaction, as well as the number and importance of partners. If no one trades with a country, then that country is not central to the network. More significantly, if only peripheral, unconnected countries trade with a country, then it is also relatively isolated from the core of the system. However, if a state trades widely with central states in the system, then that state will also rate highly in eigenvector centrality. Thus, the eigenvector centrality of a state in the international system maps closely to the core/periphery distinction because it is determined by a reciprocal system of equations that describe the relative importance of the states to which it is connected.

\section{Research Design and Findings}

Our first task is to demonstrate the relationships between diversification and eigenvector centrality in international trading networks and economic volatility. We begin by calculating the eigenvector centrality of each state using Gleditsch's expanded data on dyadic trade among countries (Gleditsch 2002). Using the same data, we also estimate the diversification of trade partners by simply counting the number of significant trading partners (that is, those with which trade exceeds $4 \%$ of GDP, as discussed in footnote 9).

Those countries that rank relatively low in eigenvector trade centrality are generally in Africa and Central Asia. Unsurprisingly, the OECD countries are at the top of the list for eigenvector centrality as well as for the traditional measure of trade openness. However, these measures do not generally move together. ${ }^{11}$ For example, unlike in the OECD countries-which trade frequently and have many central trading partners-in Latin America, there is not a single instance where a country is high in both, meaning that the countries that are most central to the global trade network are not necessarily the countries that have a high trade-toGDP ratio. To take another example, the United Arab Emirates scores lower on trade centrality than countries that trade considerably less overall. This illustrates

\footnotetext{
${ }^{11}$ Some might be concerned that the overlap between the diversification and eigenvector centrality measures will lead to problems with multicollinearity in the models that follow. However, the collinearity between the measures is only 0.34 . Furthermore, the variance inflation factor is well under 2.0, indicating that multicollinearity is unlikely to be a serious issue in this instance.
}

not only the deceptive weight that trade in commodities can introduce when examining trade alone, but also the importance of a country's trading partners; the United Arab Emirates' are Japan, South Korea, India, Thailand, and China, who themselves do not rank in the very top in terms of trade centrality.

We pit the eigenvector measure against the standard operationalization that we have already described: total trade as a share of GDP (trade). We calculate economic volatility by taking the natural $\log$ of the difference in the variable in question and then the square root of the 5-year moving average, multiplying that quantity by the square root of the number of years in the sample (25 years, for our primary specifications). We calculate volatility on five commonly used variables: output (logged GDP per capita), income (GNI per capita), final consumption, household final consumption, and investment as a share of GDP (Kim 2007; Mansfield and Reinhardt 2008). All economic data come from the World Bank's World Development Indicators.

We turn to the key independent variables from the literature on volatility in economics and political science to identify the factors that we must control for (Kim 2007). Volatility has been shown to be a function of aggregate output $(G D P)$, logged to normalize the distribution (we omit these variables for the estimations where volatility in GDP and GNI are the dependent variables); the size of a country (population), according to several scholars (Down 2007; Furceri and Ribeiro 2008); a government's ability to make decisions without constraint (constraints, operationalized here as political constraints index created by Henisz (2007)); the level of democracy in a country, which further shows how insulated politicians are from the electorate (democracy, expressed through Polity scores); the level of inflation; the stock of money in the economy $(M 2 / G D P)$; the volatility of terms of trade; and capital openness (the 12-point scale created by Reinhart and Rogoff (2004)). Economic variables were gathered from the World Bank's World Development Indicators.

Pooled time-series data sets such as this one violate the Gauss-Markov assumptions for linear estimation. The presence of relationships within countries and in particular time periods means that there will be serial correlation between observations, as well as structure in the error terms. Though there are many potential solutions to the problem, no one method will work for all types of data (Beck and Katz 1995; Wilson and Butler, unpub. data). To correct for serial correlation while avoiding the downward bias caused by including lagged dependent variables, our main specifications employ Prais-Winsten transformations, which assume an autoregressive moving-average process (Achen 2000). We also include panel-corrected standard errors to correct for unit effects.

Since listwise deletion can lead to biased coefficients as well as to inefficient estimations, we used Amelia to impute values for the missing observations (Honaker, King, and Blackwell 2007). The estimations below reflect estimations across five imputed data sets. Because our centrality measure is based on dyadic trade measures that only extend until 2000 and because many developing countries had extreme missingness on variables in the 1960s and early 1970s, we 
TABLE 1. Effects of Eigenvector Centrality on Volatility

\begin{tabular}{|c|c|c|c|c|c|}
\hline & $G D P$ & GNI & Consumption & Household consumption & Investment \\
\hline Constant & $1.92(0.32) * * *$ & $2.26(0.31) * * *$ & $1.73(0.31) * * *$ & $1.34(0.38) * * *$ & $3.23(0.42) * * *$ \\
\hline GDP & - & - & $0.05(0.04)$ & $-0.02(0.006) * * *$ & $-0.05(0.04)$ \\
\hline Population & $-0.25(0.08)^{* * *}$ & $-0.29(0.13)^{* * *}$ & $-0.17(0.06)^{* * *}$ & $-0.12(0.01)^{* * *}$ & $-0.12(0.06) * *$ \\
\hline Constraints & $-0.10(0.07)$ & $-0.06(0.07)$ & $-0.18(0.08)^{* * *}$ & $-0.01(0.008) * * *$ & $-0.10(0.05) * * *$ \\
\hline Inflation & $0.0001(0.00) * * *$ & $0.0001(0.00) * * *$ & $0.0001(0.0001)^{* * *}$ & $0.0001(0.00) * * *$ & $0.0001(0.00)^{* * *}$ \\
\hline Money supply & $-0.003(0.001)^{* * *}$ & $-0.003(0.001)^{* * *}$ & $-0.0009(0.002)$ & $-0.0003(0.0001) * * *$ & $0.0006(0.0009)$ \\
\hline Terms of trade & $0.06(0.03)$ & $0.10(0.03)^{* * *}$ & $0.10(0.03)^{* * *}$ & $0.006(0.003)^{* *}$ & $-0.03(0.02)$ \\
\hline Capital openness & $-0.02(0.03)$ & $0.008(0.02)$ & $-0.06(0.03) * *$ & $-0.003(0.002)$ & $0.03(0.02)$ \\
\hline Trade & $-0.0004(0.001)$ & $-0.002(0.001) *$ & $0.004(0.002) * *$ & $0.0002(0.0001) * *$ & $-0.0008(0.001)$ \\
\hline Diversification & $-0.0008(0.002)$ & $-0.0005(0.002)$ & $-0.0012(0.002)$ & $-0.0007(0.0002)$ & $0.003(0.002)$ \\
\hline Eigen vector centrality & $-0.23(0.08) * * *$ & $-0.23(0.08) * * *$ & $-0.28(0.10)^{* * *}$ & $-0.03(0.009) * * *$ & $-0.10(0.05)^{* *}$ \\
\hline$N$ & 5004 & 4601 & 3080 & 4381 & 5322 \\
\hline$\rho$ & .78 & .74 & .74 & .70 & .85 \\
\hline Wald $\chi^{2}$ & 18.53 & 56.01 & 22.96 & 47.84 & 10.72 \\
\hline$\rho>\chi^{2}$ & .04 & .06 & .05 & .00 & .38 \\
\hline$R^{2}$ & .03 & .06 & .05 & .13 & .04 \\
\hline
\end{tabular}

(Notes. Coefficients are derived from Prais-Winsten regressions with panel-corrected standard errors in parentheses. Estimation coefficients and statistics are averaged across five data sets; panel-corrected standard errors are a function of the variance within and across data sets.

$* p<.10, * * p<.05, * * * p<.01$.)

limited the imputations from 1976 to $2001 .^{12}$ To limit the problem of endogeneity-that is, the possibility that positive economic outcomes are driving our measures of centrality in the network—we lag both centrality measures by 1 year.

We begin with models that test the relationship between openness (trade/GDP), diversification, and eigenvector centrality on the one hand and volatility on the other. Table 1 presents the results of the full model specifications for all five measures of volatility, as described above: output (GDP), income (GNI), consumption, household final consumption, and investment as a share of GDP.

Consistent with the results of other studies in which the coefficient on trade is significant, the direction is generally positive, indicating that as trade openness increases so too does volatility (Kim 2007). However, the relationship with the trade/GDP measure is not consistent across all five measures of volatility. ${ }^{13}$

Eigenvector trade centrality has statistically significant and negative effects on volatility in all five models. In contrast, the simple measure of diversification appears to have no discernible effect on any of the volatility measures. The results indicate that the way in which one measures openness to trade is important. While trade openness may, on average, contribute to volatility, a country's position in the global trading network can actually serve to mitigate that volatility in a substantively important way.

As a further illustration, Figure 1 plots these predicted values for changes in trade as a share of GDP as well as trade centrality, across changes varying from two standard deviations away from the mean in both directions.

It is easy to see that eigenvector centrality has persistent negative and substantively significant effects on vol-

\footnotetext{
${ }^{12}$ Missingness for the variables in question was around $30 \%$. The final estimations represent average coefficients across all five data sets, with the standard errors reflecting the within- as well as the between-data set variation.

13 This inconsistency is possibly due to the fact that we have reduced Kim's period of analysis (1950-2002) to 1976-2001.
}

atility. These effects are relatively muted for household final consumption but are particularly strong for our other variables of interest, with decreases in volatility of nearly a full percentage point.

The substantive effects of eigenvector centrality in the trade network are not only more consistent in their decreases on volatility (the signs are always negative), but the magnitude of those effects are greater than for either trade as a share of GDP or of diversification. These effects are particularly strong for consumption. Moving from a mean level of centrality (for example, the average across the given time period for Guatemala) up one standard deviation (effectively, up to the position of Ireland in the international trading network) reduces consumption volatility by nearly $15 \%$.

We performed several robustness checks to test the durability of the findings. First, we ran the models for the original data set, prior to using multiple imputation. Despite the smaller number of observations and somewhat larger standard errors, the results were consistent with those presented here. Second, we ran Amelia to extend to a broader time span-from 1960 to 2007. The coefficients of interest remained unaffected, though the standard errors increased somewhat-a testament to the larger degree of missingness in those years, since the imputation algorithms produce noise in the presence of too few observations. Additionally, we ran the specifications using fixed effects for region, as well as individual fixed effects for country and year, which achieved largely similar results.

\section{Volatility and Compensation}

To underline the significance of the proposed alteration to the way that we think about the relationship between openness to trade and volatility, we turn to government spending and the compensation hypothesis.

As we noted in the introduction, as globalization has risen, it has been argued either that openness could force reductions in welfare provision due to the rise of 


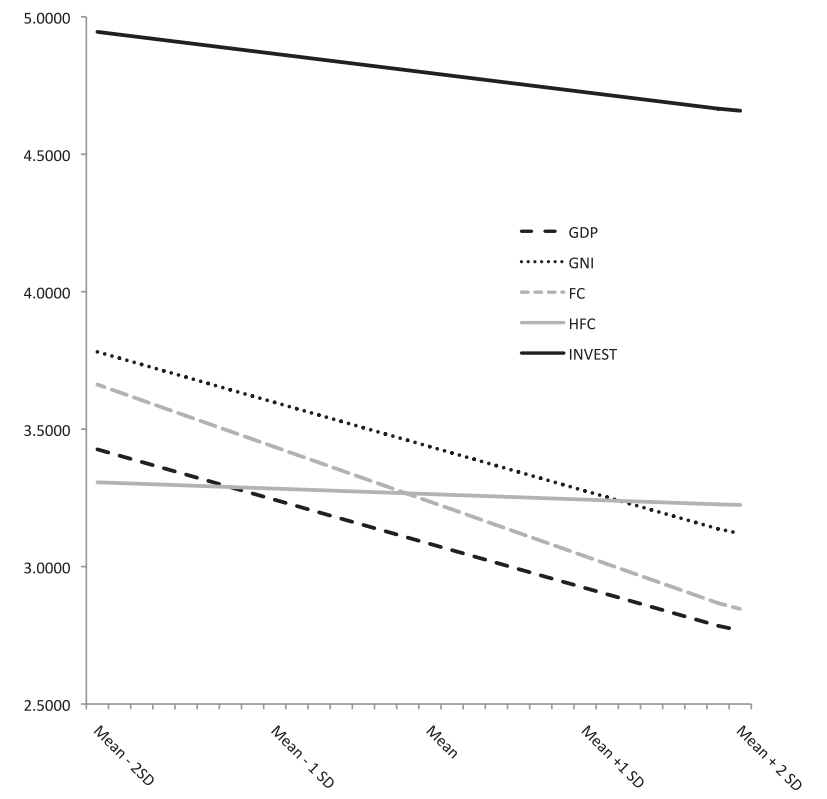

FIG 1. Effects of Eigenvector Centrality on Volatility. All Estimates Significant at the $p<.05$ level

competition or that exposure to volatility could force governments to provide compensation in return for the destabilization and displacement suffered by their citizens. However, if countries at the core of the trade network experience decreased volatility, their governments would be relatively free from the obligation to compensate, and international competitive pressures might in turn lead to drops in welfare spending, as suggested in the literature. $^{14}$

As a preliminary probe of this issue, our final task is to demonstrate the relationship between eigenvector centrality and government spending. ${ }^{15}$ Table 2 shows the results of three models that include parameters from several well-known specifications of the determinants of welfare spending, including the age dependency ratio (that is, the ratio of the combined population of children (0-14 years) and the elderly population (65 years and over)-persons in the "dependent" ages-to every 100 people); the level of output (GDP in constant US dollars); the level of democracy (polity scores); the percent of the population that lives in urban areas; and value added in manufacturing as well as in agriculture (Iversen and Cusack 2000; Rudra 2002). The findings are similar if the GDP and population variables are replaced with a single measure of GDP per capita. We also include our measure of eigenvector trade centrality, the diversification measure, and the standard trade/GDP measure.

\footnotetext{
14 There are many complex mediating links between compensation and openness to trade, no matter how the latter is measured. For example, interest groups, government partisanship, political representation, and a country's economic structure all have been hypothesized to underlie this relationship. Delineating those links precisely is beyond the scope of this article; we wish instead to establish empirically that the fundamental relationship between compensation and openness is a function of how the latter concept is theorized and that that theory has measurement implications.

${ }^{15}$ Rodrik and others also use total public spending as a share of GDP as a dependent variable, but it should be noted that many national budgets are not primarily aimed at compensation. We maintain the established research design to aid comparison, but future work could consider more specific spending on social security and welfare.
}

Model A includes just the standard measure of trade, Model $\mathrm{B}$ adds the diversification measure, and Model $\mathrm{C}$ incorporates the eigenvector measure.

The measure of eigenvector centrality in the international trade network is associated with statistically significant decreases in government spending, while the traditional total trade/GDP measure is positive. This indicates that operationalizing openness and exposure as a country's eigenvector centrality in the international trade network produces very different results than simply measuring trade as a share of GDP. Figure 2, which graphs the expected values for eigenvector indicator, provides a sense of the magnitude of the effect.

Although trade openness has a positive relationship with government spending, those changes are swamped in magnitude by the decreases in spending associated with trade centrality. Thus, for every dollar spent as compensation for an increase in trade as a share of output, a proportional increase in eigenvector centrality trade means a drop in spending of 88 cents. This suggests that countries hoping to maintain their competitive edge in the international system might consider not only the volume of trade, but a focus on acquiring varied trading partners who are themselves central to the network.

\section{Conclusion}

We hope to have expanded on the ongoing debate on the effects of globalization in two ways. First, we have demonstrated that broad connections to the international system, or deep connections with particularly important states in the international system, appear to be a key indicator of the degree of volatility that a national economy will likely suffer. Those types of connections are more important than simply having a relatively high number of trading partners. Thought of differently, this finding suggests that the core of the international economic system is considerably more insulated from volatility than is the periphery. If eigenvector centrality in the trade network is shown to decrease volatility, this illuminates the finding that a country's position in the trade network can lead to drops in welfare spending. When countries are open but are not forced to shield their citizens from the ill effects of volatility, international competitive pressures may in turn promote decreases in welfare spending. More work could potentially be done to uncover the microfoundations of the mechanisms that link centrality to volatility, and indeed volatility to spending, but these results indicate that important links exist between those phenomena.

Additionally, we have empirically demonstrated the existence of a plausible causal mechanism that links globalization and the welfare state. By showing that centrality to the trade network decreases volatility, which in turn decreases government spending, we have delineated an important step in the process by which openness impacts national governments and the public. If countries at the core of the international trading system are more insulated from volatility, their governments can forego compensation, and welfare states face the erosion of competitive pressures. Future work might examine in greater detail the links 
TABLE 2. Government Spending

\begin{tabular}{|c|c|c|c|}
\hline & $A$ & $B$ & C \\
\hline Constant & $13.80(1.31)^{* * *}$ & $13.71(1.29)^{* * *}$ & $17.92(1.44) * * *$ \\
\hline Age dependency & $2.79(1.24) * * *$ & $2.88(1.22) * * *$ & $2.18(1.22) * * *$ \\
\hline GDP & $0.01(0.10)$ & $-0.1 \quad(0.10)$ & $0.01(0.10)$ \\
\hline Percent urban & $0.03(0.01)^{* * *}$ & $0.03(0.01)^{* * *}$ & $0.03(0.01) * * *$ \\
\hline Population & $-0.71(0.13) * * *$ & $-0.73(0.13) * * *$ & $-0.68(0.13) * * *$ \\
\hline Percent manufacturing & $-0.09(0.01)^{* * *}$ & $-0.09(0.01)^{* * *}$ & $-0.08(0.01) * * *$ \\
\hline Percent agriculture & $-0.08(0.01)^{* * *}$ & $-0.08(0.01)^{* * *}$ & $-0.09(0.01) * * *$ \\
\hline Trade & $0.03(0.00)^{* * *}$ & $0.03(0.00)^{* * *}$ & $0.03(0.00)^{* * *}$ \\
\hline Diversification & & $0.01(0.01)$ & $0.01(0.01)$ \\
\hline Eigen centrality & & & $-1.19(0.21)^{* * *}$ \\
\hline$\rho$ & .70 & .70 & .68 \\
\hline$N$ & 6016 & 6016 & 5998 \\
\hline$R^{2}$ & 0.14 & 0.14 & 0.17 \\
\hline Wald $\chi^{2}$ & 366.38 & 386.56 & 477.49 \\
\hline$p>\chi^{2}$ & 0.00 & 0.00 & 0.00 \\
\hline
\end{tabular}

(Notes. Coefficients are derived from Prais-Winsten regressions with panel-corrected standard errors in parentheses. Estimation coefficients and statistics are averaged across five data sets; panel-corrected standard errors are a function of the variance within and across data sets. $* p<.10, * * p<.05, * * * p<.01$.)

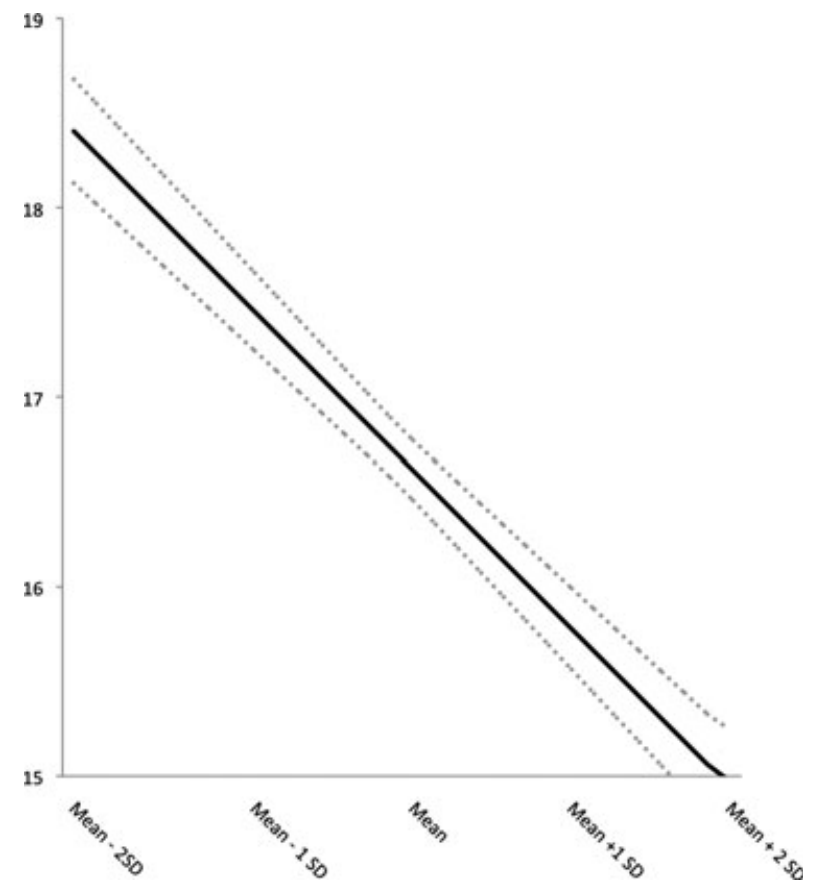

FIG 2. Effects of Eigenvector Centrality on Government Spending/GDP

between decreased volatility, pressure from interest groups, and government policy.

This study also has implications for the susceptibility of states to contagion of economic crises. The empirical evidence presented here does not immediately address the origins of financial crises, speaking instead to more standard types of economic volatility. However, the welldeveloped literature on network structure and robustness suggests that the network of relationships may be equally important in financial crises, but that the relationship between connectedness and volatility would work in precisely the opposite way. States that are linked to the core of a centralized network are likely insulated from typical volatility, but they may also be more susceptible to major shocks and crises that originate in the core of that system. As we noted in the introduction, centralized networks are robust in the sense that a smaller number of important nodes have a disproportionate number of connections and therefore insulation from disturbances at the periphery. But centralized networks are also subject to catastrophic collapse because many nodes rely on those at the core of the system-should something happen to that core, then the effects will rapidly diffuse throughout the network.

This implication of the connectedness puzzle is a prime area for future work. Such research might explore the consequences of the network location of the origins of shocks, including the magnitude of shocks between the core and the periphery of trading networks. Being peripheral may raise the aggregate vulnerability of an economy to shocks, but if being at the core results in less frequent but more significant shocks, then it is unclear which position is preferable when it comes to volatility. Similarly, an analysis of structural equivalence and other measures of centrality such as betweenness centrality could shed further insight. Such analyses could clarify whether states with structurally similar positions (beyond centrality) in the network have similar experiences with volatility.

We hope to have demonstrated that the terms on which a country integrates into the international trade network can have important effects on a country's stability and its need to cushion its domestic publics from international pressures. This finding is an important component of the consequences of openness.

\section{References}

Achen, Christopher. (2000) Why Lagged Dependent Variables Can Suppress the Explanatory Power of Other Independent Variables. The Society for Political Methodology Working Paper No 175. Available at http://polmeth.wustl.edu/mediaDetail.php?docId=175. Accessed January 23, 2010.

Alesina, Alberto, Enrico Spoloare, and Romain Wacziarg. (2003) Trade, Growth, and the Size of Countries. Harvard NOM Working Paper No. 03-14; Harvard Institute of Economic Research Working Paper No. 1995; Stanford GSB Working Paper No. RP1774. 
Alexander, C. N. (1963) A Method of Processing Sociometric Data. Sociometry 26: 268-269.

Andrews, David M. (1994) Capital Mobility and State Autonomy. International Studies Quarterly 38: 193-218.

Basinger, Scott, and Mark Hallerberg. (2004) Remodeling the Competition for Capital: How Domestic Politics Erases the Race to the Bottom. American Political Science Review 98 (2): 261-276.

Beck, Nathaniel, and Jonathan N. Katz. (1995) What to Do (and Not to Do) with Times-Series-Cross-Section Data. American Political Science Review 89: 634-647.

Birdsall, Nancy, and Amar Hamoudi. (2002) Commodity Dependence, Trade and Growth. Center for Global Development Working Paper 7. Washington, DC.

Bonacich, P. (1972) Factoring and Weighting Approaches to Status Scores and Clique Identification. Journal of Mathematical Sociology 2: 113-120.

Dollar, David. (1992) Outward-Oriented Developing Countries Really Do Grow More Rapidly: Evidence from 95 LDCs, 197685. Economic Development and Cultural Change 40: 523-544.

Dollar, David, and Aart Kraay. (2001) Growth Is Good for the Poor. The World Bank Policy Research Working Paper No. 2587.

Down, Ian. (2007) Trade Openness, Country Size and Economic Volatility: The Compensation Hypothesis Revisited. Business and Politics 9: 1-20.

Dreher, Axel, Janegbert Sturm, and Heinrich Ursprung. (2008) The Impact of Globalization on the Composition of Government Expenditures: Evidence from Panel Data. Public Choice 134: 262-292.

Edwards, Sebastian. (1993) Openness, Trade Liberalization, and Growth in Developing Countries. Journal of Economic Literature 31: 1358-1393.

Edwards, Sebastian. (1998) Openness, Productivity and Growth: What Do We Really Know? Economic Journal 108: 383-398.

Fowler, James H. (2006) Connecting the Congress: A Study of Cosponsorship Networks. Political Analysis 14: 456-487.

Freeman, Linton C. (1979) Centrality in Social Networks: Conceptual Clarification. Social Networks 1: 215-239.

Furceri, Davide, AND Marcos Poplawski Ribeiro. (2008) Government Consumption Volatility and Country Size. Centre D'tudes Prospectives et D'Informations Internationales Working Paper 2008-17. Paris, France.

Garrett, Geofrrey. (1995) Capital Mobility, Trade, and the Domestic Politics of Economic Policy. International Organization 49: 657-687.

Garrett, Geoffrey. (1998) Partisan Politics in the Global Economy. Cambridge, MA: Cambridge University Press.

Garrett, Geoffrey, and Deborah Mitchell. (1997) International Risk and Social Insurance: Reassessing the Globalization-Welfare State Nexus. New Haven, CT: Yale University.

Gleditsch, Kristen S. (2002) All International Politics Is Local: The Diffusion of Conflict, Integration, and Democratization. Ann Arbor: University of Michigan Press.

Hafner-Burton, Emilie, and Alexander Montgomery. (2006) Power Positions: International Organizations, Social Networks, and Conflict. Journal of Conflict Resolution 50: 3-27.

Hafner-Burton, Emilie, Miles Kahler, and Alexander MontGOMERY. (2009) Network Analysis for International Relations. International Organization 63: 559-592.

Henisz, Witold J. (2007) Research Programs in International Business. Progress in International Business Research 1: 15-25.

Hicks, Alexander M., and Duane H. Swank. (1992) Politics, Institutions, and Welfare Spending in Industrialized Democracies, 1960-82. The American Political Science Review 86: 658-674.

Honaker, James, Gary King, and Matt Blackwell. (2007) Amelia II: A Program for Missing Data. Available at http://gking.harvard.edu/cem/.

Huckfeldt, Robert, Paul Allen Beck, Russell J. Dalton, and Jefrrey Levine. (1995) Political Environment, Cohesive Social Groups, and the Communication of Public Opinion. American Journal of Political Science 39: 1025-1054.
Iversen, Torben, and Thomas R. Cusack. (2000) The Causes of Welfare State Expansion: Deindustrialization or Globalization? World Politics 52: 313-349.

Jackson, Matthew O. (2008) Social and Economic Networks. Princeton, NJ: Princeton University Press.

Kahler, Miles (Eds.) (2009) Networked Politics: Agency, Power and Governance. Ithaca, NY: Cornell University Press.

Kali, Raja, and Javier Reyes. (2006) The Architecture of Globalization: A Network Approach to International Economic Integration. Journal of International Business Statistics 38: 595-620.

Kim, So-Yeoung. (2007) Openness, External Risk, and Volatility: Implications for the Compensation Hypothesis. International Organization 61: 181-216.

Krueger, Anne O. (1998) Why Trade Liberalisation Is Good for Growth. The Economic Journal 108: 1513-1522.

LAzER, DAvid. (2003) Information and Innovation in a Networked World. In Dynamic Social Network Modeling and Analysis: Workshop Summary and Papers, edited by Kathleen M. Carley, Ronald L. Breiger, and Philippa Pattison. Washington, DC: National Academies Press, 101-118.

Leamer, Edward. (1988) Measures of Openness. In Trade Policy and Empirical Analysis, edited by Robert Baldwin. Chicago: Chicago University Press, 145-204.

Lee, Dwight R., and Richard B. Mckenzie. (1989) The International Political Economy of Declining Tax Rates. National Tax Journal 42: 7983.

Mansfield, Edward D., and Eric Reinhardt. (2008) International Institutions and the Volatility of International Trade. International Organization 62: 621-652.

Marin, Bernd, and Renate Mayntz, (Eds) (1992) Policy Networks: Empirical Evidence and Theoretical Considerations. Boulder: Westview Press.

Marsh, D., And Ron A. W. Rhodes. (1992) Policy Communities and Issue Networks: Beyond Typology. In Policy Networks in British Government, edited by D. Marsh, and Ron A. W. Rhodes. Oxford, UK: Oxford University Press, 90-119.

Mintrom, Michael, and Sandra Vergari. (1998) Policy Networks and Innovation Diffusion: The Case of State Education Reforms. Journal of Politics 60: 126-148.

Noel, M. Tichy, Michael L. Tushman, and Charles Fombrun. (1979) Social Network Analysis for Organizations. Academy of Management Review 4: 507-519.

Oates, William. (1972) Fiscal Federalism. New York: Harcourt Brace Jovanovich.

Prasad, Eswar S., Kenneth S. Rogoff, Shang-Jin Wei, and M. Ayhan Kose. (2004) Financial Globalization, Growth and Volatility in Developing Countries. NBER Working Paper No. 10942.

Quinn, Dennis. (1997) The Correlates of Change in International Financial Regulation. American Political Science Review 91: 531-551.

Reinhart, Carmen M., and Kenneth Rogoff. (2004) The Modern History of Exchange Rate Arrangements: A Reinterpretation. Quarterly Journal of Economics 119 (1): 1-48.

Rodriguez, Francisco, and Dani Rodrik. (2000) Trade Policy and Economic Growth: A Skeptic's Guide to the Cross-National Evidence. NBER Macroeconomics Annual 15: 261-325.

Rodrik, Dani. (1997) Has Globalization Gone Too Far? Washington, DC: Institute for International Economics.

Rodrik, DANi. (1998) Why Do More Open Economies Have Bigger Governments? Journal of Political Economy 106: 997-1032.

Rudra, Nita. (2002) Globalization and the Decline of the Welfare State in Less Developed Countries. International Organization 56: 411-445.

RUdRA, NitA. (2004) Openness, Welfare Spending, and Inequality in the Developing World. International Studies Quarterly 48: 683-709.

Scotт, John. (1991) Social Network Analysis: A Handbook. London: Sage Publications.

von Stein, Jana. (2008) The International Law and Politics of Climate Change: Ratification of the United Nations Framework Convention and the Kyoto Protocol. Journal of Conflict Resolution 52: 243-268. 